\title{
THE RELATIONSHIP BETWEEN EXECUTIVE FUNCTIONS AND FLOW IN LEARNING
}

\author{
Tajana LJUBIN GOLUB, Majda RIJAVEC, Diana OLCAR \\ University of Zagreb, Faculty of Teacher Education \\ Zagreb, Croatia \\ E-mail: tajana.ljubingolub@ufzg.hr
}

\begin{abstract}
The aim of the study is to assess the relationship between executive functions and flow experiences in learning. Female college students assessed their flow in learning activities and performed phonemic verbal fluency task (PVF) and a lexical Stroop task. Flow in learning was associated with performance on the PVF task, but not with the lexical Stroop task. In addition, flow in learning mediated the effects of verbal fluency performance on the Grade Point Average (GPA), while inhibition and controlled selective attention measured by the lexical Stroop test had direct effects on the GPA. Results suggested that the better executive functions embodied in verbal fluency task are cognitive correlates of flow. The results are also in line with the neurobiological model of flow pointing to brain regions that are suggested to be involved in language processing and the prefrontal brain region.
\end{abstract}

Key words: flow, phonetic verbal fluency, lexical Stroop, neuropsychological tests, GPA

\section{Introduction}

Flow is a highly enjoyable, optimal psychological state people feel when they are so focused on a task that it amounts to complete absorption in an activity (Csikszentmihalyi, 1975). The essential component of flow is the centring of attention on a limited stimulus field with the exclusion of distrac-

\footnotetext{
Acknowledgment

We wish to thank the students for their participation in the research, and the anonymous reviewer for his helpful comments on the earlier version of the article.
}

Declaration of Conflicting Interests

The authors declared no potential conflicts of interest with respect to the research, authorship, and/or publication of this article. tions from consciousness (Csikszentmihalyi, 1990). According to Csikszentmihalyi (1997), any activity can produce flow as long as there is a balance between the challenging task, which demands intense concentration and commitment, and one's skill level. Flow was found to be related to higher levels of well-being (Csikszentmihalyi, 1975, 1990; 1997; Hunter \& Csikszentmihalyi, 2003) and higher achievement (e.g., Bakker, 2008; Jackson, Thomas, Marsh, \& Smethurst, 2001). In the educational context, flow was found to be associated with higher levels of commitment to education and progress through the school curriculum (Carli, Delle Fave, \& Massimini, 1988; Csikszentmihaly, Rathunde, \& Whalen, 1993), and higher academic achievement at college (Engeser \& Rheinberg, 2008; Engeser, Rheinberg, Vollmeyer, \& Bischoff, 2005).

DOI: $10.21909 /$ sp.2016.01.706 
Although there is a lot of research on psychological correlates, studies on biological and neuropsychological correlates of flow have been rare (for a review, see Peifer, 2012). Flow has been found to correlate with cardiovascular, respiratory and EMG measures (de Manzano, Theorell, Harmat, \& Ullen, 2010; Gaggioli, Cipresso, Serino, \& Riva, 2013), suggesting relative sympathetic enhancement during flow. Electromyography studies found that flow is associated with increased activity in zygomatic major muscle (indicator of positive affect, controls smiling, Larsen, Norris, \& Cacioppo, 2003) (de Manzano et al., 2010) and decreased activity in corrugator supercilii (indicator of negative affect, controls frowns) (Kivikangas, 2006), suggesting a positive valence of emotion during flow, i.e. enjoyment. Neural correlates of experimentally induced flow during arithmetic calculation (as indexed by cerebral blood flow activity) includes both increased activity in the left putamen, the left inferior frontal gyrus (IFG) and posterior cortical regions, and decreased neural activity during flow in the medial prefrontal cortex (MPFC) and left amygdala (Ulrich, Keller, Hoenig, Waller, \& Groen, 2014). Changes in neural activity in left IFG and left amygdala were correlated with subjectively experienced flow. The authors suggested that an increase of neural activity in the putamen possibly reflects increased outcome probability, and those in the left IFG might reflect a deeper sense of cognitive control. Decrease of neural activity in MPFC was attributed to decreased self-referential processing and decrease of neural activity in amygdala was considered to reflect positive emotionality during flow (Ulrich et al., 2014).

Overall, studies have pointed to the importance of studying the biological corre- lates of flow. However, there is no published study investigating the association between flow and neuropsychological cognitive functions, which are considered to be measures of brain functions and may underlie flow experience. Especially interesting are cognitive control processes that regulate thought and behavior, known under the term executive functions (EF). Executive functions are considered to be a set of correlated but separable control processes that regulate lowerlevel cognitive processes in support of goaldirected behavior (Friedman et al., 2008). Although conceptualizations vary regarding what components of executive functions might be, most frequently EF include: inhibition of automatic, or prepotent response; updating working memory representations, shifting/switching between tasks or mental sets (Friedman et al., 2008); but also include sustained and selective attention (Alvarez \& Emory, 2006), and dual-tasking (Logie, Cocchini, Della Sala, \& Baddeley, 2004), among others. From the point of neuropsychology, experiencing flow in an activity implies that several EF are involved: the ability to concentrate on the task and to sustain deep focus on it while excluding distractions, the inhibition of response to irrelevant stimuli, self-regulation, mental flexibility, control processes for co-ordinating and adjusting goal-directed behaviors which enable the control of performance according to the criteria given, and the smooth performance associated with flow.

The phonemic or letter verbal fluency (VF) task is a longstanding and widely used neuropsychological measure of executive functioning (e.g., Henry \& Crawford, 2004; Troyer, Moscovitch, \& Winocur, 1997) that requires the generation of words starting with a given letter cue (Benton, Hamsher, \& Sivan, 1994; 
Indefrey \& Levelt, 2000; Lezak, Howieson, Bigler, \& Tranel, 2012). VF is thought to impose considerable cognitive demands consistent with most definitions of executive functioning and is therefore considered to be the valid measure of EF (Alvarez \& Emory, 2006; Henry \& Crawford, 2004). The task requires self-initiated retrieval and efficient organization of verbal retrieval and recall, self-monitoring aspects of cognition (the participant must keep track of responses already given), and inhibition of responses when appropriate (supression of the habitual behavior of using words in a manner related to their meaning) (Perret, 1974). It also requires cognitive flexibility, or ability to create and change search strategies based primarily on lexical representations - in order to be efficient in memory retrieval, a person must flexibly shift from one strategy of retrieval (e.g., animals with first letter ,p") to another (e.g., switching to retrieval of nouns with the starting letters "po", then ,pi“", etc).

Persons with frontal lobe damage, especially left lobe, showed impairad phonemic VF (e.g., Troyer, Moscovitch, Winocur, Alexander, \& Struss, 1998). Neuroimaging studies of VF on healthy participants done by functional magnetic resonance imaging (fMRI), have consistently found the left inferior frontal gyrus (IFG) as the main neural region activated by the phonological VF task. Other regions included in the neural network involve the anterior cingulate cortex (ACC), the middle (left) prefrontal cortex (PFC), lateral temporal cortex, insula, precuneus, and cerebellum (Baldo, Schwartz, Wilkins, \& Dronkers, 2006; Costafreda, David, \& Brammer, 2009; Friedman et al., 1998; Fu et al., 2002; Lurito, Kareten, Lowe, Chen, \& Mathews, 2000; Schlösser et al., 1998).
Another popular EF measure is the Stroop test (Stroop, 1935), which measures inhibitory cognitive control and selective attention by assessing the ease with which a person can keep a goal in mind and suppress a habitual response in favor of a less familiar one (Strauss, Sherman, \& Spreen, 2006). It is regarded as a measure of effectiveness of focused attention and also as a test of EF because of the inhibitory control which it requires (Lezak et al., 2012, p. 416). The stimuli in the test are either congruent or incongruent. For example, in the color Stroop test the word "BLUE" is displayed in the ink color blue or red (congruent or incongruent, respectively) and a participant is asked to name the ink color of a color word. In the incongruent condition, the person experiences interference because of the conflict between two attributes of the same stimulus, thus leading to slower reaction time to the incongruent stimuli. The effect is a robust one and was named the Stroop effect. Stroop lesion studies showed that the performance is sensitive to lateral and superior medial lesions of the frontal lobes (reviewed in Alvarez \& Emory, 2006). Neuroimaging studies suggested that Stroop test activates a neural network of both frontal and nonfrontal regions: inferior frontal cortex, parietal cortex, anterior cingulate cortex (ACC), posterior cingulate and motor and premotor regions (for review see Alvarez \& Emory, 2006). Based on the event-related potential and fMRI studies, Carter and van Veen (2007) proposed that the dorsal anterior cingulate cortex (ACC) has a prominent and specific role in cognitive control as a conflict monitor, i.e. to detect conflict between simultaneously active, competing representations and to engage the dorsolateral prefrontal cortex to resolve such conflict. 


\section{The Current Study}

Based on the involvement of executive processes in flow, we propose that a positive correlation between the indicators of EF and flow may be expected (Hypothesis 1). To measure aspects of EF, two commonly used neuropsychological tests were applied: the phonetic VF task (Lezak et al., 2012) and the letter Stroop task (Ravnkilde, Videbech, Rosenberg, Giedde, \& Gade, 2002). Both tasks are in the verbal domain, since we were specifically interested in flow in learning, and academic activities providing opportunities for experiencing flow in learning are mainly of a verbal type, i.e. they involve language.

Given that flow is supposed to facilitate academic achievement (Csikzentmihaly et al., 1993; Engeser \& Rheinberg, 2008), it was expected that flow in learning would be positively related to academic achievement measured as grade point average (GPA) (Hypothesis 2). There is also strong evidence that executive functioning contributes to academic achievement (e.g., Best, Miller, \& Naglieri, 2011). However, no study has investigated the relationship between EF, flow and academic achievement. Based on the idea that advanced executive functioning may be relevant both to experiencing flow and better academic achievement, we propose that flow in learning mediates the relationship between advanced EF and higher academic achievement (Hypothesis 3 ).

Based on the above, the following hypotheses were tested:

$\mathrm{H} 1$ : Indicators of executive functions, verbal fluency performance and Stroop test performance will be positively associated with flow experience in learning;
$\mathrm{H} 2$ : Flow experiences in learning will be positively related to GPA;

H3: Flow experiences in learning will mediate the expected relationship between executive functions (as measured by verbal fluency and Stroop task) and GPA.

Previous studies found gender differences in respect to VF and verbal abilities (Gauthier, Duyme, Zanca, \& Capron, 2009; Halpern, 1994) with women scoring higher than men, and also found gender differences in cerebral activation associated with covert VF task (Gauthier et al., 2009), emphasizing the need to consider sex in studies of VF. Also, there are age and education effects on phonemic VF (Pendleton, Heaton, Lehman, \& Hulihan, 1982; Zimmermann, Parente, Joanette, \& Fonseca, 2014), although some studies did not reveal age effect on VF in adult population (e.g., Cauthen, 1978; Cohen, 2000). To control for these factors, the participants of the same sex, age, and education level were included in the study.

\section{Method}

\section{Participants and Procedure}

The sample comprised 87 female students from the University of Zagreb, Faculty of Teacher Education, aged from 19 to 23 years, with a mean age of 20 years $(M=19.92 ; S D=$ 0.63 ), all of them Croatian native speakers. They participated voluntarily and anonymously during the regular course in psychology.

\section{Measures}

1. Flowscale. Flow scale was used for measuring the quality offlow experience in learning activities. The respondents rated their 
subjective experience while engaged in learning activities, using a 12-item Likert-like scale developed by Mayers (1978; as cited in Delle Fave \&Massimini, 1988). The flow scale measures the theory-based components of flow experience on an 8-point scale, ranging from 1 ("do not agree at all") to 8 ("completely agree"). The questionnaire was administred in Croatian language form, using the standard back translation strategy(Hambleton, 1994).

2. Written verbal fluency task. The subjects were first instructed to write as many words as possible that begin with the letter "P" within 3 minutes, and after that they were required to write as many words as they can recall that begin with the letter " $\mathrm{S}$ " within next 3 minutes. The VF test with letters "P" and " $\mathrm{S}$ " is usually used in Croatia, because of the frequency of the words with these letters (Momirović \& Kovačević, 1970). The score is the number of the correct admissible words generated for the two letters ( $\Sigma$ PS; for each letter the result is a total number of responses minus repetitions and inappropriate responses such as the same word with a different suffix, or words that do not begin with the target letter).

3. Lexical version of the Stroop test. The lexical version of the Stroop test (Rimac, Žebec, \& Jurić, 2006) consists of 232 words, out of which fifty percent are the words "big" and fifty percent are the words "small". Fifty percent of the words are written in uppercase letters (e.g., "BIG" and "SMALL") and the rest in lowercase letters (e.g., "big" and "small"), and their semantic contents and position are random on the lines and the pages. The participants' task was to cross out as many of the total words "small" and "SMALL", regardless of the upper case or lower case letters. The subjects were also instructed not to skip words or lines, and the duration of the task was one minute. The test has proven to have good validity (Rimac et al., 2006). The number of words crossed out correctly was used as a test result.

4. Academic achievement. Academic achievement was measured by self-reported GPA. GPA has been shown to be a relatively reliable indicator of student academic achievement (see Noftle \& Robins, 2007).

\section{Results}

\section{Descriptive Statistics}

\section{Associations Among Study Variables}

Descriptive statistics and bivariate correlations among study variables are displayed

Table 1 Descriptive statistics and zero-order Pearson correlation coefficients among study variables $(N=87)$

\begin{tabular}{lcccc}
\hline Variables & 01 & 02 & 03 & 04 \\
\hline (01) Flow in learning & - & $.332^{* *}$ & -.040 & $.326^{* *}$ \\
(02) Verbal fluency & & - & $.303^{* *}$ & $.188^{*}$ \\
(03) Lexical Stroop test & & & - & $.234^{*}$ \\
$(04)$ GPA & & & & - \\
\hline$M$ & 62.0 & 65.6 & 86.9 & 3.78 \\
$(S D)$ & $(11.83)$ & $(13.0)$ & $(12.26)$ & $(0.34)$ \\
Range & $28-89$ & $38-94$ & $62-115$ & $3.0-4.6$ \\
\hline
\end{tabular}

Note. ${ }^{*} \mathrm{p}<.05,{ }^{*} \mathrm{p}<.01$ 
in Table 1. As predicted, verbal fluency was significantly correlated with reported flow in learning $(r=0.332, p<.01)$. Correlations between VF and each item of the flow scales were also inspected, since the items describe different components of flow experience. Significant negative correlations were found with items 7 (I get bored, $r=-.203, p<.05$ ) and 8 (I have to make an effort to keep my mind on what is happening, $r=-.319, p<$ $.01)$ and positive correlations with items 9 (I would do it even if I didn't have to, $r=$ $.269, p<.01$ ) and 12 (I enjoy the experience, and/or the use of my skills, $r=.246, p<.05$ ). It seems that verbal fluency is associated with specific flow components, effortless concentration and resulting enjoyment in the activity. The result in the lexical Stroop test was not significantly correlated with flow in learning. Therefore, the results partially supported Hypothesis 1, in so far as the VF was used as a measure of executive functions.

In line with Hypothesis 2, GPA correlated positively with flow in learning $(r=.326, p<$ $.01)$. Interestingly, GPA correlated with the lexical Stroop task $(r=.234, p<.05)$, but not with the VF task $(p>.05)$. A regression analysis with flow in learning, verbal fluency and the lexical Stroop, entered as predictors of GPA, showed that a $17 \%$ variance of GPA can be explained, with the lexical Stroop and flow in learning being significant predictors ( $\beta=.262, p<.05 ; \beta=p<0.01$, respectively).

\section{Mediating Effects of Flow}

The mediating role of flow in learning in the relationship between different aspects of executive functions (measured by VF task and Stroop task) and GPA was tested using the SPSS macro, PROCESS (Hayes, 2012). The macro provides an estimate of the indi- rect effect in the population by resampling the dataset k-times (we repeated the bootstrap process 5,000 times). An estimate is considered statistically significant if its $95 \%$ confidence interval (CI) does not include zero.

While controlling for the Stroop result, the direct effect of verbal fluency on GPA was not statistically different from zero $(p>0.70)$, but the indirect effect was positive and statistically different from zero, as evidenced by a $95 \%$ bias-corrected bootstrap CI that was entirely above zero ( 0.0013 to 0.0067$)$. On the other hand, while controlling for verbal fluency, the Stroop test performance demonstrated direct effect on GPA, while indirect effect was not statistically different from zero, as evidenced by a $95 \%$ bias-corrected bootstrap CI that included zero $(-0.0040$ to 0.0002$)$. In summary, higher phonetic verbal fluency, but not Stroop performance, influenced GPA indirectly through flow experiences in learning. In addition, better Stroop performance, but not verbal fluency, had direct effects on GPA. Thus, the results are partially in line with Hypothesis 3 , showing the mediating role of flow in learning in the relationship between the $\mathrm{EF}$ as measured by VF task (but not as measured by Stroop task), and GPA.

\section{Discussion}

The main aim of this study was to investigate the relationship among executive functions, flow in learning, and GPA. Phonetic verbal fluency (PVF) task and Stroop task were used for measuring executive functions.

As predicted, it was found that flow in learning was associated with better phonetic verbal fluency. Correlation analysis on the item level of the Flow scale suggests that 
PVF is in relation to only some items, i.e. specific flow components - effortless concentration and resulting enjoyment in the activity. The PVF task includes all core processes involved in word production (Indefrey \& Levelt, 2000), but also measures executive functions, especially mental flexibility and is therefore considered to "give the greatest scope to subjects who can figure out a strategy for guiding a search for words, and are most difficult for subjects who cannot develop strategies on their own" (Lezak et al., 2012, p. 693). However, since the VF task involves both executive functions and verbal abilities, a so-called task impurity problem (Burgess, 1997), it may also be that the verbal aspect of the VF task, and not EF is associated with flow experiences and consequently, the GPA. This study was not designed to resolve whether the EF or verbal abilities are the key factor associated with flow experiences. The problem of impurity may be alleviating by the use of latent variable as measure of EF, extracted from multiple tasks selected to have different nonexecutive abilities but to tap the same underlying executive function (Bollen, 1989). This task impurity problem is especially emphasized when a task used tap multiple aspects of executive functioning. In future studies, it will be important to introduce controls for any non-executive demand, but also to use measures of specific executive functions.

Structural and functional imaging studies have shown that both the PVF task (Gauthier et al., 2009) and the flow state induced experimentally by mathematic calculation (Ulrich et al., 2014) activates left IFG. It seems that neural network activated in flow during mathematic calculation and in highly efficient VF performance partly corresponds. In the light of these neurobiological studies of VF, our results suggest that the EF involved in the (efficiently performed) verbal fluency task and the corresponding brain regions are relevant cognitive and neurobiological correlates of flow in learning. In other words, it may be that high VF performers are prone to experience flow because of their improved EF and especially mental flexibility associated with lower activation in ACC.

On the other hand, experiencing flow in learning was not associated with the EF involved in lexical Stroop test result. Stroop test is considered as a measure of inhibition (Alvarez \& Emory, 2006) and there is consensus that inhibition is dissociable from other EFs (Miyake et al., 2000). The specific characteristic of flow is that it requires a type of effortless concentration in which a person is absorbed and enjoys the activity. The Stroop task seems to involve forced concentration on the task, continuously producing a mental conflict, and is not accompanied by enjoyment and positive emotions. This may be the reason why flow experiences were not found to correlate with performance in the Stroop task. Ullen and colleagues (2012) argued that flow may be a state of effortless attention that relies on mechanisms different from those involved in attention during mental effort. Our results are in line with this, revealing that inhibition and selective attention accompanied by attention conflict, as measured by the Stroop task, is not the mechanism underlying flow experiences.

As concerning the relationship between EF and academic achievement, this study found a positive relationship between the components of EF as measured by lexical Stroop test and GPA, but not between EF measured by the VF performance and GPA. Bootstrap regression analyses revealed that the participants' Stroop task performance has 
a positive and direct effect on GPA, thus suggesting that cognitive mechanisms underlying the Stroop task, e.g. inhibitory control, mental efficiency and selective attention in difficult conditions, i.e. in cognitively incongruent tasks, are relevant for academic achievement. This is in line with several earlier studies that also documented the relationship between inhibitory control measured by the Stroop test and school achievement (McClelland et al., 2007; St. Clair-Thompson \& Gathercole, 2006). Inhibitory processes may aid performance by allowing students to hold the problem in the working memory, to shift focus between different aspects of the problem, and to suppress the tendency to respond to salient but irrelevant elements of the problem (Blair \& Razza, 2007). There are several possible reasons why verbal fluency did not correlate with GPA. VF is a component of creativity, and creativity is usually a less valid predictor of scholastic achievement (Gralewski \& Karwowski, 2012). Students' creativity is not always desirable for teachers, who often ignore or even punish them for creative behavior (Westby \& Dawson, 1995). In addition, our sample consisted of exclusively female students. Some studies showed that creativity correlates with academic achievement in most of the subjects for male, but not for female, students (Gras, Bordoy, Ballesta, \& Berna, 2010).

In line with previous research (Engeser \& Rheinberg, 2008), in this study flow experiences in learning were found to be positively associated with academic achievement. As predicted, the results also revealed that flow in learning mediates the link between advanced verbal fluency and academic achievement, thus suggesting that advanced cognitive and neuropsychological functions embodied in higher phonetic verbal fluency may lead to a higher tendency to experience flow in learning, which in turn may lead to higher GPA.

The relationship found between verbal fluency, flow and GPA is probably not due solely to intelligence (intelligent people have better verbal abilities, doing better in school and having more flow experiences), since previous research revealed no connection between flow and general cognitive ability (Ullen et al., 2012), and flow has been shown to contribute to GPA independently of basic abilities, such as verbal intelligence (Engeser $\&$ Rheinberg, 2008). However, (verbal) intelligence was found to be associated with verbal fluency (Bolter, Long, \& Wagner, 1983) such as that the VF task discriminates better among individuals with low verbal intelligence regardless of lesion location. In addition, efficient PVF performance reflects not only EF and verbal abilities, but also psychomotor speed (Cauthen, 1978), word knowledge, and/or verbal long-term memory (Ruff, Light, Parker, \& Levin, 1997).

Regarding practical implications, the results suggest that students with low verbal fluency might benefit from cognitive training aimed at improving the underlying cognitive components of verbal fluency (e.g., cognitive flexibility, strategic retrieval, selfmonitoring). This in turn can facilitate their flow in learning experiences, leading to higher GPA. Also, training in inhibitory control may have a beneficiary effect on academic achievement, independently of student's performance in verbal fluency.

The study has several limitations. The current sample comprised only female participants, and prior literature has suggested gender differences in verbal fluency (Loonstra, Tarlow, \& Sellers, 2001). Although this does not necessarily imply that the cor- 
relation pattern would change across gender, it is questionable to generalize the current results to men. This study measures flow in relation to letter fluency tasks that have been found to be especially sensitive to frontostriatal deficits, while category fluency tasks tend to be sensitive to temporal lobe pathology (Henry \& Crawford, 2004). Therefore, the results of our study cannot be generalized to other types of verbal fluency (e.g., category fluency).

It should also be noted that although we suggested the following directionality: advanced (EF involved in) $\mathrm{VF} \rightarrow$ higher flow $\rightarrow$ higher GPA, alternative directionality, i.e. higher flow $\rightarrow$ improved (EF involved in) VF $\rightarrow$ higher GPA may be proposed. We tested this alternative mediational model ${ }^{1}$ and it was not statistically significant. However, our study is not of experimental nor longitudinal type and, therefore, our model should be confirmed in studies with designs aimed to test directionality.

Although frequency and intensity/quality are both important indices of flow, in this study we focused only on quality of flow because not all flow experiences are the same (Csikszentmihalyi, 1987; as cited in Moneta, 2012). Nevertheless, future studies should address the frequency of flow experiences as well.

Also, as discussed earlier, another important limitation is that it cannot be ruled out that it is the verbal aspect of the task and not executive functions, that is associated with

\footnotetext{
${ }^{1}$ We also tested the alternative mediational model: more flow experiences $\rightarrow$ improved (executive functions involved in) verbal fluency $\rightarrow$ higher GPA (controlling for the Stroop test result). Indirect effect was not found, as evidenced by a $95 \%$ bias-corrected bootstrap CI that included zero (-.0020 to .0024).
}

flow experiences and consequently, with the GPA, since the study was not designed to separate verbal abilities and EF.

However, the current study is the first known study to demonstrate an association between phonetical verbal fluency and flow experience in learning, thus contributing to our knowledge of neuropsychological correlates and underlying cognitive mechanisms of flow.

Received January 27, 2015

\section{References}

Alvarez, J. A., \& Emory, E. (2006). Executive function and the frontal lobes: A meta-analytic review. Neuropsychology Review, 16(1), 17-42. doi: 10.1007/s1 1065-006-9002-x

Bakker, A. B. (2008). The work-related flow inventory: Construction and initial validation of the WOLF. Journal of Vocational Behavior, 72, 400-414. doi:10.1016/j.jvb.2007.11.007

Baldo, J. V., Schwartz, S., Wilkins, D., \& Dronkers, N. F. (2006). Role of frontal versus temporal cortex in verbal fluency as revealed by voxelbased lesion symptom mapping. Journal of the International Neuropsychological Society, 12, 896-900. doi:10.1017/S1355617706061078

Benton, A., Hamsher, K., \& Sivan, A. (1994). Multilingual Aphasia Examination, (3rd Ed.). Iowa City, IA: AJA Associates.

Best, J. R., Miller, P. H. \& Naglieri, J. A. (2011). Relations between executive function and academic achievement from ages 5 to 17 in a large, representative national sample. Learning and Individual Differences, 21(4), 327-336. doi: 10.1016/j.lindif.2011.01.007.

Blair, C., \& Razza, R. P. (2007). Relating effortful control, executive function, and false-belief understanding to emerging math and literacy ability in kindergarten. Child Development, 78, 647663. doi: 10.1111/j.1467-8624.2007.01019

Bollen, K. A. (1989). Structural Equations with Latent Variables. New York: Wiley.

Bolter, J. F., Long, C. J., \& Wagner, M. (1983). The utility of the Thurstone Word Fluency Test in identifying cortical damage. Clinical Neuropsychology, 5, 77-82. 
Burgess, P. W. (1997). Theory and methodology in Executive Function research. In P. Rabbitt (Ed.), Methodology of frontal and executive function (pp. 81-116). Hove, UK: Psychology Press.

Carli, M., Delle Fave, A., \& Massimini, F. (1988). The quality of experience in the flow channels: Comparison of Italian and U.S. students. In M. Csikszentmihalyi, I. S. Csikszentmihalyi (Eds.), Optimal experience: Psychological studies of flow in consciousness (pp. 288-306). Cambridge, UK: Cambridge University Press.

Carter, C. S., \& van Veen, V. (2007). Anterior cingulate cortex and conflict detection: An update of theory and data. Cognitive, Affective, \& Behavioral Neuroscience, 7(4), 367-379. doi:10. 3758/CABN.7.4.367

Cauthen, N. (1978). Verbal fluency: Normative data. Journal of Clinical Psychology, 34, 126-129. doi 10.1002/1097-4679(197801)34:1<126::AIDJCLP2270340129>3.0.CO;2-6

Cohen, M. J. (2000). On the reliability, validity and cognitive structure of the Thurstone Word Fluency Test. Archives of Clinical Neuropsychology, 15(3), 267-279. doi: 10.1093/arclin/15.3. 267

Costafreda, S. G., David, A. S., \& Brammer, M. J. (2009). A parametric approach to voxel-based meta-analysis. Neuroimage, 46, 115-122. doi: 10.1016/j.neuroimage.2009.01.031

Csikszentmihalyi, M. (1975). Beyond boredom and anxiety. San Francisco, CA: Jossey-Bass.

Csikszentmihalyi, M. (1990). Flow: The psychology of optimal experience. New York: Harper \& Row.

Csikszentmihalyi, M. (1997). Finding flow. New York, NY: Basic Books.

Csikszentmihalyi, M., Rathunde, K., \& Whalen, S. (1993). Talented teenagers: The roots of success and failure. Cambridge, UK: Cambridge University Press.

de Manzano, Ö., Theorell, T., Harmat, L., \& Ullén, F. (2010). The psychophysiology of flow during piano playing. Emotion, 10(3), 301-311. doi: 10.1037/a0018432

Delle Fave, A., \& Massimini, F. (1988). Modernization and the changing contexts of flow in work and leisure. In M. Csikszentmihalyi, I. S. Csikszentmihalyi (Eds.), Optimal experience: Psychological studies of flow in consciousness (pp. 192-213). Cambridge, UK: Cambridge University Press.

Engeser, S., \& Rheinberg, F. (2008). Flow, performance and moderators of challenge-skill balance.
Motivation and Emotion, 32, 158-172. doi:10. 1007/s11031-008-9102-4

Engeser, S., Rheinberg, F., Vollmeyer, R., \& Bischoff, J. (2005). Motivation, Flow-Erleben und Lernleistung in universitären Lernsettings [Motivation, flow-experience, and performance in learning settings at universities]. Zeitschrift für Pädagogische Psychologie, 19, 159-172. Retrieved from http://www.uni-trier.de/fileadmin/ $\mathrm{fb} 1 /$ prof/PSY/PGA/bilder/Engeser Rheinberg Vollmeyer_Bischoff_2005.pdf

Friedman, L., Kenny, J. T., Wise, A. L., Wu, D., Stuve, T. A., Miller, D. A., ... \& Lewin, J. S. (1998). Brain activation during silent word generation evaluated with functional MRI. Brain and Language, 64, 231-256. doi: 10.1006/brln.1998. 1953

Friedman, N. P., Miyake, A., Young, S. E., DeFries, J. C., Corley, R. P., \& Hewitt, J. K. (2008). Individual differences in executive functions are almost entirely genetic in origin. Journal of Experimental Psychology and Genetics, 137(2), 201-225. doi: 10.1037/0096-3445.137. 2.201 .

Fu, C. H. Y., Morgan, K., Suckling, J., Williams, S. C. R., Andrew, C., Vythelingum, G. N., \& McGuire, P. K. (2002). A functional magnetic resonance imaging study of overt letter verbal fluency using a clustered acquisition sequence: Greater anterior cingulate activation with increased task demand. Neuroimage, 17(2), 871-879. doi: 10.1006/ nimg.2002.1189

Gaggioli, A., Cipresso, P., Serino, S., \& Riva, G. (2013). Psychophysiological correlates of flow during daily activities. Studies in Health Technology and Informatics, 191, 65-69. doi: 10.3233/978-1-61499-282-0-65

Gauthier, C. T., Duyme, M., Zanca, M., \& Capron, C. (2009). Sex and performance level effects on brain activation during a verbal fluency task: A functional magnetic resonance imaging study. Cortex, 45, 164-176. doi:10.1016/j.cortex.2007. 09.006

Gralewski, J., \& Karwowski, M. (2012). Creativity and school grades: A case from Poland. Thinking Skills and Creativity, 7(3), 198-208. doi:10.1016/ j.tsc.2012.03.002

Gras, R., Bordoy, M., Ballesta, G., \& Berna, J. (2010). Creativity, intellectual abilities and response styles: Implications for academic performance in the secondary school. Anales De Psicologia, 26(2), 212-219. Retrived from http://www.um.es/ analesps/v26/v26_2/03-26_2.pdf 
Halpern, D. F. (1994). Gender differences in intellectual abilities. In R. J. Sternberg (Ed.), Encyclopedia of Human Intelligence (pp. 463-467). New York: Macmillan.

Hambleton, R. K. (1994). Guidelines for adapting educational and psychological tests: A progress report. European Journal of Psychological Assessment, 10, 229-244.

Hayes, A. F. (2012). PROCESS: A versatile computational tool for observed variable mediation, moderation, and conditional process modeling [White paper]. Retrieved from http://www. afhayes.com/public/process2012.pdf

Henry, J. D., \& Crawford, J. R. (2004). A metaanalytic reveiw of verbal fluency performance following focal cortical lesions. Neuropsychology, 18(2), 284-95. doi:10.1037/0894-4105.18. 2.284

Hunter, J. P., \& Csikszentmihalyi, M. (2003). The positive psychology of interested adolescents. Journal of Youth and Adolescence, 32, 27-35. doi: $10.1023 / \mathrm{A}: 1021028306392$

Indefrey, P., \& Levelt, W. J. M. (2000). The neural correlates of language production. In M. Gazzaniga (Ed.), The new cognitive neurosciences ( $2^{\text {nd }}$ ed.) (pp. 845-865). Cambridge, MA: MIT Press.

Jackson, S. A., Thomas, P. R., Marsh, H. W., \& Smethurst, C. J. (2001). Relationship between flow, self-concept, psychological skill, and performance. Journal of Applied Sport Psychology, 13, 129-153. doi: 10.1080/ 104132001753149865

Kivikangas, J. M. (2006). Psychophysiology of flow experience: An explorative study (Unpublished Master Thesis, University of Helsinki, Helsinki, Finland). Retrived from http://ethesis.helsinki.fi/ julkaisut/kay/psyko/pg/kivikangas/psychoph.pdf

Larsen, J. T., Norris, C. J., \& Cacioppo, J. T. (2003). Effects of positive and negative affect on electromyographic activity over zygomaticus major and corrugator supercilii. Psychophysiology, 40, 776-785. doi: 10.1111/1469-8986.00078

Lezak, M. D., Howieson, D. B., Bigler, E. D., \& Tranel, D. (2012). Neuropsychological Assessment $\left(5^{\text {th }}\right.$ ed.) New York: Oxford University Press.

Logie, R. H., Cocchini, G., Della Sala, S., \& Baddeley, A. D. (2004). Is there a specific executive capacity for dual task coordination? Evidence from Alzheimer's disease. Neuropsychology, 18(3), 504-513. doi: 10.1037/0894-4105. 18.3 .504

Loonstra, A. S., Tarlow, A. R., \& Sellers, A. H. (2001). COWAT Metanorms across age, educa- tion, and gender. Applied Neuropsychology, 8(3), 161-166. doi: 10.1207/S15324826AN0803_5 Lurito, J. T., Kareten, D. A., Lowe, M. J., Chen, S. H., \& Mathews, V. P. (2000). Comparison of rhyming and word generation with fMRI. $H u$ man Brain Mapping, 10, 99-106. doi: 10.1002/ $1097-0193(200007) 10: 3 \% 3$ C 99:: A ID HBM1 0\%3E3.0.CO;2-Q

McClelland, M. M., Cameron, C. E., Connor, C. M., Farris, C. L., Jewkes, A. M., \& Morrison, F. J. (2007). Links between behavioral regulation and preschoolers' literacy, vocabulary, and math skills. Developmental Psychology, 43(4), 947-959. doi: 10.1037/0012-1649.43.4.947

Miyake, A., Friedman, N. P., Emerson, M. J., Witzki, A. H., Howerter, A., \& Wager, T. D. (2000). The unity and diversity of executive functions and their contributions to complex "frontal lobe" tasks: A latent variable analysis. Cognitive Psychology, 41, 49-100.

Momirović, K., \& Kovačević, V. (1970). Evaluacija dijagnostičkih metoda. [Evaluation of diagnostic methods]. Zagreb: Republic Office for Employment.

Moneta, G. B. (2012). On the measurement and conceptualization of flow. In S. Engeser (Ed.), Advances in flow research (pp. 23-50). New York: Springer.

Noftle, E. E., \& Robins, R. W. (2007). Personality predictors of academic outcomes: Big five correlates of GPA and SAT scores. Journal of Personality and Social Psychology, 93, 116-130. doi:10.1037/0022-3514.93.1.116

Peifer, C. (2012). Pychophysiological correlates of flow-experience. In S. Engeser (Ed.), Advances in flow research (pp. 139-164). New York: Springer. doi: 10.1007/978-1-4614-2359-1_8

Pendleton, M. C., Heaton, R. K., Lehman, R. A., \& Hulihan, D. (1982). Diagnostic utility of the Thurstone Word Fluency Test in neuropsychological evaluations. Journal of Clinical Neuropsychology, 4, 307-317. doi: 10.1080/ 01688638208401139

Perret, E. (1974). The left frontal lobe of man and the suppression of habitual responses in verbal categorical behaviour. Neuropsychologia, 12, 323-330. doi: 10.1016/0028-3932(74)90047-5

Ravnkilde, B., Videbech, P., Rosenberg, R., Giedde, A., \& Gade, A. (2002). Putative tests of frontal lobe function: A PET-study of brain activation during Stroop's Test and verbal fluency. Journal of Clinical and Experimental Neuropsychology, 24(4), 534-47. doi:10.1076/jcen.24.4.534.1033 
Rimac, I., Žebec, M. S. \& Jurić, D. (2006). Verbalna, neobojena papir-olovka verzija Stroop testa metrijske osobine. [Verbal uncolored paper-andpencil version of the Stroop test - metric properties]. In V. Ćubela Adorić, Z. Penezić, A. Proroković, A. Vulić-Prtorić (Eds.), $15^{\text {th }}$ Days of psychology in Zadar: Abstracts (pp. 116). Zadar, Croatia: University of Zadar, Department of Psychology.

Ruff, R. M., Light, R. H., Parker, S. B., \& Levin, H. S. (1997). The psychological construct of word fluency. Brain and Language, 57, 394-405. doi: 10.1006/brln.1997.1755

Schlösser, R., Hutchinson, M., Joseffer, S., Rusinek, H., Saarimaki, A., Stevenson, J., ... \& Brodie, J. D. (1998). Functional magnetic resonance imaging of human brain activity in a verbal fluency task. Journal of Neural Neurosurgery Psychiatry, 64, 492-498. doi: 10.1136/jnnp.64.4.492

St Clair-Thompson, H. L., \& Gathercole, S. E. (2006). Executive functions and achievements in school: Shifting, updating, inhibition, and working memory. The Quarterly Journal of Experimental Psychology, 59, 745-759. doi: 10.1080/ 17470210500162854

Strauss, E., Sherman, E. M. S., \& Spreen, O. (2006). A compendium of neuropsychological tests: Administration, norms, and commentary ( $\left.3^{\text {rd }} \mathrm{ed}.\right)$. Oxford: Oxford University Press.

Stroop, J. (1935). Studies of interference in serial verbal reactions. Journal of Experimental Psychology, 18, 643-662. Retrived from http:// psych.hanover.edu/classes/Cognition/papers/ stroop\%201933.pdf
Troyer, A. K., Moscovitch, M., \& Winocur, G. (1997). Clustering and switching as two components of verbal fluency: Evidence from younger and older healthy adults. Neuropsychology, 11(1), 138-46. doi: 10.1037/08944105.11.1.138

Troyer, A. K., Moscovitch, M., Winocur, G., Alexander, M. P., \& Stuss, D. (1998). Clustering and switching on verbal fluency: The effects of focal frontal- and temporal-lobe lesions. Neuropsychologia, 36, 499-504. doi: 10.1016/ S0028-3932(97)00152-8

Ullen, F., de Manzano, O., Almeida, R., Magnusson, P. K. E., Pedersen, N. L., Nakamura, J., ... \& Madison, G. (2012). Proneness for psychological flow in everyday life: Associations with personality and intelligence. Personality and Individual Differences, 52, 167-172. doi:10.1016/ j.paid.2011. 10.003

Ulrich, M., Keller, J., Hoenig, K., Waller, C., \& Groen, G. (2014). Neural correlates of experimentally induced flow experiences. Neuroimage 86, 194-202. doi: 10.1016/j.neuroimage. 2013. 08.019 .

Westby, E. L., \& Dawson, V. L. (1995). Creativity: Asset or burden in the classroom? Creativity Research Journal, 8(1), 1-10. doi: 10.1207/ s15326934crj0801_1

Zimmermann, N., Parente, M. A. M. P., Joanette, Y., \& Fonseca, R. P. (2014). Unconstrained, phonemic and semantic verbal fluency: Age and education effects, norm and discrepancies. Psicologia: Reflexăo e Crítica, 27(1), 1-9. doi: 10.1590/S0102-79722014000100007

\section{APENDIX}

Flow Scale (Myers, 1978):

1. I get involved.

2. I get anxious.

3. I clearly know what I am supposed to do.

4. I get direct clues as to how well I am doing.

5. I feel I can handle the demands of the situation.

6 . I feel self-conscious.

7. I get bored.

8. I have to make an effort to keep my mind on what is happening.

9. I would do it even if I didn't have to.

10. I get distracted.

11. Time passes more slowly or more quickly.

12. I enjoy the experience and the use of my skills. 